\title{
The Nature and Meaning of Social Integration for Young Children With Mild Developmental Delays in Inclusive Settings
}

\section{MICHAEL J. GURALNICK}

University of Washington

This paper examines fundamental conceptual, methodological, and outcome issues with respect to the social integration of preschool-age children with mild developmental delays in inclusive early childhood settings. Cast within a developmental-ecological framework, social integration is evaluated in terms of three constructs: (1) the connectedness of peer interactions; (2) the quality of interpersonal relationships; and (3) the nature of adjustments that occur during social exchanges. A general model of factors that influence social integration and their interrelationships is presented as a means of organizing future intervention activities to promote social integration.

One expectation of inclusive practices is that meaningful social relationships will form between children with and without special needs as they become familiar with one another in early childhood settings. This expectation that social integration will occur with respect to children's peer relationships and friendships seems reasonable because inclusive practices emphasize principles and values that seek to maximize respect for individual differences in develop-

it, ensure equal access, and foster a sense of selonging to a common community (Guralnick, 1978, 1990). Ideally, we would hope that inclusive early childhood programs would be characterized by children's willingness to understand, go beyond, accept, and even overlook developmental differences, unusual behavior patterns, or certain physical characteristics of their peers, and establish productive social relationships. To support the development of these positive relationships between children with and without special needs, the programmatic design of quality early childhood settings should exemplify inclusive principles and values by promoting full participation of all children in social and nonsocial activities, and by adapting and accommodating to children's special needs.

In view of the importance of what is certainly a core issue in our field, the degree to which the goal of social integration has been achieved in inclusive preschool settings is examined in this paper. To do so, a conceptual and methodological framework is established first to characterize the nature and meaning of social integration in inclusive settings. This is followed by a section in which the available data on social integration are organized and evaluated within this framework. Finally, two general approaches designed to promote social integration are considered, and a general model relating factors influencing social integration is presented.

It is important to note that this discussion will be limited to preschool-age children with mild developmental (cognitive) delays.' This

\footnotetext{
' The population of children with mild developmental (cognitive) delays described in this paper was carefully defined using wellaccepted criteria based on intelligence test scores and measures of adaptive behavior. Specific exclusionary criteria also were established with respect to children's behavior problems, sensory deficits, motor impairments, and communication disorders. Etiology of the delay (when known) was not considered, as the categorical definition was applied uniformly. Of note, within this relatively homogenous and well-defined population. only weak associations are obtained between peer-related social competence and intelligence or language measures, although behavior problems are more strongly correlated (Guralnick, Connor, Hammond, Gottman, \& Kinnish, 1996a; Guralnick \& Groom 1985). Individual differences in peer interactions and social integration appear to be related to more process-type factors (see text). Other well-defined populations, such as children with communication disorders, are likely to exhibit patterns different from those found for children with mild developmental delays (e.g.. Guralnick, Connor, Hammond. Gottman. \& Kinnish. 1996b).
} 
is a relatively high incidence group even at the preschool level; one that generally is included in typical preschool or daycare settings. Moreover, by focusing on children with mild developmental delays, a framework for examining critical developmental and context issues can be established; something not readily accomplished for heterogeneous groups of children. In fact, it will be argued that both developmental and ecological perspectives are essential for a complete understanding of social integration in inclusive settings for this group of children. Such a perspective may encourage similar approaches for other well-defined groups of children.

\section{THE MEANING OF SOCIAL INTEGRATION}

Unfortunately, no generally accepted criteria exist that can inform us about the extent to which social integration has been achieved. Consequently, a framework that carefully specifies expectations for specific patterns of social integration outcomes is needed. These expectations can then be evaluated to determine if specified outcomes have been realized. Of importance, establishing expectations is somewhat arbitrary and will vary with the purpose or value framework developed to guide the analysis. A reasonable approach (though perhaps idealized) is to expect full integration to be found across all specified social interaction dimensions. Other approaches may establish lower expectations or may anticipate differences in social integration for different dimensions of social interaction or differences depending upon whether assessments are obtained from the perspective of children with or without developmental delays. The important point is that expectations are made explicit.

Conceptually, an outcomes-based framework assumes that identified patterns of social integration meaningfully represent variations in children's social experiences. Correspondingly, it assumes that a methodology is available or can be constructed in which measures can be derived to index identified social integration patterns. There are few domains in development, however, that are more difficult to conceptualize or to assess than the domain of peer-related social development (Howes, 1988). The complexity of this issue becomes apparent when we realize what must be considered: (a) the various manifestations of social integration (e.g., active acceptance, passive integration, exclusion, rejection), (b) the varying strengths of a relationship (e.g., acquaintanceship, intimate friendship), (c) the different types of data (e.g., observational, phenomenological), (d) the specific characteristics of playmates (e.g., chronological age, gender), and (e) the context in which peer interactions take place (e.g., free-play or structured activities; dramatic play or motor-oriented activities). Thus, the first challenge for an outcomes approach is to define (with expectations) and measure the dimensions of social integration as represented in inclusive settings. Then, we must examine the available data in relation to this set of expectations and dimensions.

\section{EVALUATING SOCIAL INTEGRATION OUTCOMES}

To establish an outcomes framework, three social integration constructs and corresponding measures are defined and examined: (a) the connectedness (or extent) of peer interactions; (b) the quality of interpersonal relationships; and (c) the nature of adjustments that occur during social exchanges. Data relevant to each of these three social integration constructs in relation to interactions occurring between children with and without developmental delays are presented.

It is important to point out that the social integration of children with mild developmental delays will be evaluated in relation to typically developing chronological age mates. Despite the fact that children with mild developmental delays are less developmentally advanced than typically developing children of the same age, parents view typically developing age mates as the appropriate reference group for their child (Guralnick, Connor, \& Hammond, 1995). In addition, social integration as evaluated within the framework of 
the three social integration constructs will primarily take place from the perspective of the typically developing children. Moreover, in this analysis, the expectation (hypothesis) is that complete social integration is achieved when typically developing children are connected to and maintain the same quality of interpersonal relationships with children with mild developmental delays as they do with children without delays. This analysis further assumes that for complete social integration to occur, typically developing children must make appropriate adjustments to the unique developmental characteristics of children with delays. This ideal, but by no means unreasonable, expectation is examined below.

Most studies of social integration have included heterogeneous groups of children with disabilities, often consisting of children exhibiting a range of motor, cognitive, behavioral, and communicative disabilities. In my earlier review of the social integration literature (Guralnick, 1981a), the interactions of typically developing children with other typically developing children formed the reference point from which to evaluate the extent of integration for diverse groups of children with disabilities. Despite the heterogeneity of the participants and measures, one particularly consistent pattern emerged from these important early studies (Cavallaro \& Porter, 1980; Guralnick, 1980; Ispa \& Matz, 1978; Peterson \& Haralick, 1977; Porter, Ramsey, Tremblay, Iaccobo, \& Crawley, 1978; White, 1980). Specifically, the degree of social separation increased as a function of the severity of the child's disability. Of importance, despite considerable within group variability, social separation was observed even for children with mild disabilities. Moreover, more recent studies continue to document similar patterns. Whether indexed by social exchanges, prosocial behaviors, or friendships, or assessed via observational or peer sociometric measures, diverse groups of preschool-age children with disabilities are less preferred playmates by typically developing children than are other typically developing children (e.g., Blackmon \& Dembo, 1984; Nabors, 1997; Strain, 1984). Unfortunately, the generally small number of participants found in the studies of social integration has not allowed analyses of specific subgroups of children, such as children with mild developmental delays who are the focus of this paper. The value of "specificity," i.e., selecting well-defined and more homogeneous subgroups of children, has been emphasized for the domain of social integration (Buysse \& Bailey, 1993; Guralnick, 1981b) and for the general field of early intervention (Guralnick, 1997b, 1998). In addition, existing groups of children with and without disabilities usually have been observed in these studies, yet few efforts have been made to control for relevant child and family characteristics such as chronological age, gender, socioeconomic status, or familiarity. In the absence of these experimental controls, it is difficult to interpret findings on social integration within a developmental framework.

The only series of studies in which relatively homogenous groups of children with mild developmental delays can be separately analyzed is that of Guralnick and his colleagues (Guralnick et al., 1998; Guralnick, Connor, Hammond, Gottman, \& Kinnish, 1996a; Guralnick, Gottman, \& Hammond, 1996; Guralnick \& Groom, 1987, 1988a; Guralnick \& Paul-Brown, 1984, 1986, 1989). Consequently, only results from this research program will be presented. It is important to note that children in this series of studies participated in short-term (2-4 weeks) playgroups created specifically for research purposes. Although the playgroup methodology offers many advantages (e.g., precise matching of subjects, children free of reputation bias), its conclusions may be limited to specific features of the playgroup parameters. Thus, to assess the generalizability of the findings, comparisons also will be made to related research.

\section{Connectedness}

Most would agree that the extent to which children with and without developmental delays are socially connected with one another constitutes an important aspect of what is meant by social integration. The critical question based on expectations established for this 
analysis, however, is whether all children are equally connected socially, irrespective of their developmental status. From a quantitative perspective, it is possible to determine whether or not children with and without developmental delays interact with one another to the extent represented simply by their availability in the preschool setting. As such, the extent to which children show a preference for playmates based on developmental level serves as a key index of social integration. Connectedness, however, is likely to vary in terms of the social demands placed on the play partners. Passive type play (e.g., parallel, onlooker) places the least demands; interactive social exchanges, such as those occurring during associative or group play, consistently place more demands on a relationship; and maintaining a friendship is clearly the most demanding form of connectedness.

As might be expected, when available data are examined in relation to each of the three major dimensions of connectedness (i.e., passive play, interactive play, friendship), different patterns of social integration are found. For passive play measures such as parallel play or onlooker behavior, social separation is found to exist between children with and without developmental delays, but only to a relatively minor extent in comparison to assessments of more interactive play. In contrast, social separation is clearly evident for more socially interactive forms of play. This is particularly the case when interactive play consists of extended and active social exchanges such as positive social interactions or group play (Guralnick et al., 1996a; Guralnick \& Groom, 1987). Generally, for interactive measures of social integration, typically developing children interact with children with developmental delays about half as often as expected, based on the number of children available in the two groups (typically developing, mildly delayed).

Within group variation is certainly apparent, but perhaps the most salient observation is the substantial separation that exists between children with and without mild development delays for more extended and active social exchanges. In fact, despite individual differences for these interactive measures, data from a recent study revealed no overlap for the 95\% confidence intervals of the means for children with and without delays. Only one delayed child received social interactions from typically developing children above the mean for typically developing children interacting with other typically developing children, and approximately $80 \%$ of typically developing children prefer other typically developing children to children with developmental delays (Guralnick et al., 1996a).

The high level of social integration found for more passive measures, however, suggests that children with mild developmental delays do have numerous opportunities for observational learning in relation to typically developing children. Because the children often play in close proximity to one another, passive play may well evolve into more active forms of play. Bakeman and Brownlee (1980) observed that parallel play often serves as a stepping-stone to group play for typically developing children, and this also may be the case for children with mild developmental delays (Guralnick \& Hammond, in press). Findings for the passive measures also address a frequently stated expectation of inclusion; that of equal access. Based on this passive measure of social integration, children with and without delays seem to move about play areas freely, engaging in activities of interest without regard to the developmental status of their peers.

The most demanding and rewarding aspects of social relationships emerge when young children establish dyadic friendships (see Howes, 1988; Newcomb \& Bagwell, 1995). A unilateral friendship is said to occur when one child prefers a peer (usually indicated by spending more time with or more frequently interacting positively with a specific peer), but the peer does not show a similar preference for that child. Nevertheless, a clear preference is exhibited by one child. These unilateral friendships are observed among a substantial proportion of preschool children, including children with mild developmental delays. When analyzed in terms of the developmental characteristics of the friend selected, typically 
developing children choose peers with mild delays to a much lesser extent than would be expected based on their availability (Guralnick et al., 1996a; Guralnick \& Groom, 1988a). When reciprocal friendships are evaluated (mutual preferences for one another), typically developing children strongly prefer other typically developing children. Of note, children with mild delays have considerable difficulties forming reciprocal friendships in general (Guralnick et al.; Guralnick \& Groom).

\section{Interpersonal Relationships}

Another perspective on social integration can be obtained by examining the content of direct interpersonal exchanges. What is the quality of those interactions? Are children with and without developmental delays treated similarly by typically developing children? Is there evidence that typically developing children actively isolate or reject children with developmental delays and does this contribute to the patterns of social separation identified in the previous section on connectedness?

It is important to note that based on a variety of measures, the vast majority of interactions occurring between children with and without developmental delays are positive in both content and style. In fact, a composite measure based on social exchanges judged to be negative does not indicate that children with mild delays are singled out for poor treatment by typically developing children (Guralnick et al., 1996a). There are, however, some fairly subtle indicators suggesting interpersonal difficulties. An intensive analysis based on an utterance-by-utterance evaluation of socialcommunicative exchanges occurring between children with and without delays revealed a number of concerns. Specifically, when typically developing children request children with delays to do something, they direct a smaller proportion of joint requests such as "let's" or "we," and they justify their requests less frequently. In addition, typically developing children direct a greater proportion of strong, particularly unmitigated directives (e.g., "Do this!" "Give me that!") to children with delays than to other typically developing children, and they share information less often (Guralnick \& Paul-Brown, 1984, 1989). Although exchanges are not generally hostile or unusually negative, disagreements occur more frequently when typically developing children interact with children with mild delays than when they interact with other typically developing children (Guralnick \& Paul-Brown, 1989). This suggests the existence of a stressful relationship between children with and without developmental delays. In fact, interpersonal stress is particularly apparent during conflict situations. Under those circumstances, typically developing children are more negative and less positive to children with mild developmental delays than to other similar age typically developing children (Guralnick et al., 1998).

Findings consistent with both the connectedness and interpersonal relationship measures of social integration are obtained when typically developing children are asked to rate their playmates in terms of the extent to which they like to play with a particular child (Asher, Singleton, Tinsley, \& Hymel, 1979). When these peer sociometric ratings are carried out, typically developing children rate children with delays as much lower (less overall acceptance) and children with delays generally receive fewer positive and more negative ratings (Guralnick et al., 1996a; Guralnick \& Groom, 1987).

\section{Accommodations}

For social interactions to be productive, participants must thoughtfully adapt not only to the context but to the unique characteristics, styles, and abilities of their partner. When interacting with children of different ages, for example, adjustments must be made relative to the cognitive and linguistic characteristics of the playmate; an adjustment that is observed to occur even for preschool children (e.g., Shatz \& Gelman, 1973). Children with mild developmental delays, however, pose unusually difficult challenges for their typically developing chronological age mates. That is, discrepancies existing between a peer's chronological age and his or her developmental characteristics must somehow be resolved. 
Moreover, appropriate adjustments by typically developing children to their playmate's cognitive, linguistic, and socioemotional characteristics reflect not only a sensitivity to complex individual differences, but also a willingness to work hard to initiate and maintain connectedness to diverse types of children.

Interestingly, despite evidence of the interpersonal stress noted above, when typically developing children interact with developmentally delayed children they make a number of important adjustments that appear to be responsive to differing developmental characteristics of their companions, particularly their cognitive and linguistic levels. Specifically, to better ensure appropriate communication, typically developing children use more directives, clarify messages more often, and rely more upon multiple modes of communication, particularly nonverbal strategies when interacting with children with developmental delays (Guralnick \& Paul-Brown, 1984, 1989). These findings are consistent with typically developing children taking more responsibility to organize play; an area of special concern for children with developmental delays (Guralnick \& Groom, 1985, 1987).

\section{Developmental Framework}

The analyses presented above clearly suggest that, from the perspective of typically developing chronological age mates, children with developmental delays are, for the most part, not thoroughly integrated socially. The extent to which children with developmental delays are isolated from same age typically developing children varies with the measure selected, but the pattern is nevertheless apparent. It is possible, however, that the behavior of typically developing children toward children with developmental delays constitutes a reasonable (from their perspective) pattern of social interactions, one consistent with the $d e$ velopmental level of the children with delays. Put simply, typically developing children may be interacting with children with mild developmental delays as they would with younger typically developing children; i.e., social interaction and preference patterns therefore are occurring on the basis of a peer's develop- mental level rather than developmental status. Although one might argue that even social isolation of younger children is inappropriate, such chronological age separation may well be normative (e.g., Strayer, 1980). Consequently, this circumstance provides a developmental explanation for the observed patterns of social separation involving similar age children with mild developmental delays. If this explanation constitutes a valid alternative to separation based on the existence of a child's disability (i.e., delay), then establishing expectations for social integration outcomes in inclusive settings should consider these findings. That is, the expectations established for social integration might be more appropriately linked to patterns based on children's developmental level. Again, the choice of expectations for social integration will depend on the purposes and value framework articulated by those conducting the analysis.

To rule out this developmental explanation, a matched group of younger typically developing children is required. Studies of children with delays that fail to include such a comparison group (matched at minimum on the basis of developmental level) leave open the alternative developmental explanation for any social integration differences observed between chronological age mates with and without developmental delays. For studies in which matched groups of younger typically developing children have been included, available evidence indicates that children with mild developmental delays experience social separation for most measures even beyond that which occurs for the matched group of younger typically developing children (Guralnick et al., 1998; Guralnick \& Groom, 1987; Guralnick \& Paul-Brown, 1989). Although a developmental level explanation can account for some of the differences discussed above (e.g., typically developing children rate delayed age mates as negatively as they rate developmentally matched younger typically developing children and they use similar strategies with both groups during conflicts), the central patterns of social separation identified earlier remain. Accordingly, it is something to do with children's developmental status rather 
than their developmental level that is responsible for much of the social separation that emerges when children with developmental delays interact with typically developing chronological age mates in inclusive settings.

Of considerable importance is that analyses of the interaction patterns of younger typically developing children with the same developmental level as the children with delays present a similar and occasionally even more severe pattern of social separation from children with developmental delays as obtained for typically developing chronological age mates (Guralnick et al., 1998; Guralnick \& Groom, 1987, 1988a; Guralnick \& Paul-Brown, 1989). In many respects, younger typically developing children may have more difficulty (perhaps being less skillful) accommodating to children with delays than older typically developing children, especially during conflicts (Guralnick et al.).

Some contradictory findings, however, are found when "older" ( 5 to 6 year old) children with developmental delays are observed interacting with younger typically developing children. Specifically, patterns of social separation are not as apparent as patterns of separation that occur with chronological age mates (Guralnick \& Paul-Brown, 1986; Ispa \& Matz, 1978). Although matching on developmental level was not used in these studies of older children with delays, children with and without delays were certainly more similar to one another developmentally because there was a chronological age discrepancy. Additional work using appropriate matching is needed to determine if kindergarten-age children with mild delays exhibit different patterns of social integration with younger typically developing children than do preschool-age children with mild delays.

\section{Perspective of Children with Developmental Delays}

The preceding discussion has focused exclusively on social integration from the perspective of typically developing children. Similar analyses, however, can be carried out from the perspective of children with mild developmental delays. When playing, do children with mild delays have preferences for other children with delays or for typically developing children? Does the developmental status of the play partner affect responsiveness to the social bids of children with mild delays? Do children with mild delays experience interpersonal difficulties to a different extent when interacting with children with or without developmental delays? This is dependent in part on the ability of children with delays to connect with peers, some of whom may be reluctant or even difficult play partners. The ability of children with developmental delays to make the connections, however, constitutes an important index of social integration from their perspective. Many proponents of inclusion may consider this form of social integration to be of most significance and establish expectations accordingly.

Interestingly, available evidence indicates that when children with mild delays engage in more interactive social play such as group play, conversation, or rough and tumble play, they either show no preference or prefer to interact with typically developing age mates (Guralnick et al., 1996a; Guralnick \& Groom, 1987). Global assessments of acceptance based on peer sociometric measures, however, reveal that children with mild delays do prefer typically developing children. Similarly, for unilateral friendships, when children with mild delays reveal a preference, it is for typically developing children (Guralnick et al., 1996; Guralnick \& Groom, 1988a). Children with mild delays also offer more joint directives (let's, we) to typically developing children than to other children with mild delays (Guralnick \& Paul-Brown, 1989). For more passive measures such as parallel play, however, a preference for one group or another is generally not evident (Guralnick et al., 1996a; Guralnick \& Groom, 1987). Similarly, only minor differences as a consequence of peers' developmental status are apparent with respect to responsiveness to the social bids of children with delays, although there is some tendency for the responsiveness of typically developing children to children with delays to decrease over time (Guralnick et al., 1996a; Guralnick \& Groom, 1987). 
From an interpersonal perspective, similar to the experiences of typically developing children, children with mild delays have fewer difficulties with typically developing children than with other children with mild delays. They use fewer strong directives, share information more, have fewer disagreements, and are less negative and more positive during conflicts with typically developing children than with children with mild delays (Guralnick et al., 1998; Guralnick \& Paul-Brown, 1989).

\section{Psychological Meaning of Social Separation}

Taken together, evidence suggests that an absence of complete social integration exists from the perspective of typically developing children, especially for measures that require more intensive or intimate social relationships. Instances in which typically developing children overtly reject children with developmental delays are found, but this is not a dominant pattern. In contrast, it appears that social separation occurs primarily through a process of exclusion. As such, typically developing children simply prefer other typically developing children and may ignore or avoid children with delays. For the most part, despite more frequent disagreements, special difficulties occurring during conflicts, and the use of more demanding forms of speech, social exchanges between children with and without developmental delays are generally cordial, and there is little evidence suggesting an unusually negative style of interacting. In addition, typically developing children appear to recognize differences in their playmates' abilities and adjust interactions accordingly. Typically developing children, however, do rate children with mild delays less positively and more negatively when judging children with whom they like to play.

As important as these objective assessments of social integration are, we have few insights into the personal meaning for those children being socially separated along the various dimensions identified earlier. Does objectively defined social separation correspond to subjective experiences of rejection and impair the self-esteem of children with mild developmental delays? If so, do these adverse effects hold only for certain dimensions (e.g., friendships) of social separation? On the other hand, is it possible that the subjective experiences of social separation as defined objectively result in only transient levels of discomfort?

Even if we had the tools, it would be difficult to isolate the psychological impact of social separation on children with mild developmental delays because social separation occurs in the context of many positive and perhaps beneficial social experiences involving typically developing children. We know that, when given a choice, children with mild developmental delays often prefer and seek out typically developing chronological age mates, and their experiences with typically developing children are more productive than those that occur with other mildly delayed children (e.g., more positive, less negative, share information more) (see Guralnick et al., 1998). Moreover, it does not appear that the presence of a large proportion of typically developing children in inclusive settings suppresses the social relationships or the social interactions of children with mild developmental delays. Both unilateral and reciprocal friendships occur at the same rate in inclusive or segregated settings (Guralnick et al., 1996a). In addition, although the proportion of negative interactions is increased slightly in inclusive settings, the social interaction levels of children with delays have consistently been found to be higher in inclusive as opposed to segregated settings (Buysse \& Bailey, 1993; Guralnick et al., 1996a; Guralnick \& Groom, 1988b).

\section{Generality of Patterns of Social Separation}

To what extent do these patterns of social separation generalize to different contexts? Every study, or even series of studies, is constrained by its own unique research strategies and limited set of parameters. The generality of the playgroup strategy is of particular concern. Despite offering important controls over familiarity among children and subject selection, legitimate questions can be raised about the representativeness of the social interaction 
patterns and the stability of those patterns over time. These critical issues are discussed next.

With regard to whether free-play social interactions occurring in the playgroups are representative of free-play interactions occurring in more typical preschool programs, available evidence suggests that the playgroups are indeed ecologically valid settings. In particular, social play patterns among children develop in the playgroups as would be expected based on the developmental literature (Guralnick \& Groom, 1987). Moreover, children with developmental delays exhibiting more socially competent behavior during free-play in the playgroups as evaluated through observational measures are judged to be more socially competent in community settings as evaluated by their parents (Guralnick \& Hammond, in press). The general absence of constraints in free play and the use of toys and materials similar to those in other studies further minimizes the possibility that the playgroups produce an unusual pattern of social interactions.

The short-term nature of the playgroups ( $2-4$ weeks), however, leaves open the possibility that social integration patterns may change over time through processes related to children becoming more familiar with one another. Moreover, most quality inclusive preschools make concerted efforts to both foster social integration and to encourage acceptance of individual differences. Over time, children may respond favorably to these efforts, thereby producing social integration patterns different from those obtained in short-term playgroups.

As noted earlier, none of the published nonplaygroup studies separate out the social integration patterns of children with mild developmental delays. Virtually all studies included children with heterogeneous types and severity of disability. Moreover, the programs included children with disabilities who often were older (usually by 1 year) than the typically developing children. Nevertheless, as discussed earlier, even for studies that primarily included children with mild disabilities, evidence supports the overall social integration patterns found in the playgroups. Related studies further suggest that only minor changes in these patterns occur over time. For example, the proportion of social interactions of children with disabilities directed toward typically developing children did not change over a 2 month period, despite continued intensive efforts to promote social interaction and social integration (Jenkins, Odom, \& Speltz, 1989). Similarly, time did not have any impact on the preference patterns of older children with mild delays and typically developing children (Guralnick, 1980). In a more recent study, Diamond, LeFurgy, and Blass (1993) described an inclusive preschool program that provided specific teaching about disability and diversity issues. Despite these efforts, peer sociometric measures revealed that children with disabilities were rated lower in acceptance than same-age typically developing children, and that status remained throughout the school year. Interestingly, evidence for more complete social integration has been obtained from studies in which children with mild disabilities were older (especially 1 year or more) than their typically developing classmates and demonstrated social play skills similar to those of typically developing children (Ispa \& Matz, 1978). Other studies show that, over time, some positive social integration changes occur for children with disabilities but not for typically developing children, although it is unclear what level of social integration is actually achieved (Dunlop, Stoneman, \& Cantrell, 1980). However, even under seemingly ideal conditions (e.g., high levels of social skills exhibited by children with disabilities and a supportive, quality program), social separation is apparent well into the school year (Ispa, 1981). Relatedly, preference patterns for typically developing children, especially negative relationships, either remain stable or become increasingly selective and negative over the course of the preschool year (Ramsey, 1995).

Accordingly, in the series of studies utilizing the playgroup methodology, patterns of social integration for children with mild developmental delays appear to be robust. Similar findings are obtained across a wide range of program types, subject samples, times of the year, measures, and efforts to promote so- 
cial integration and social skills. This is not to say that quality inclusive programs are not able to promote social integration over time. There is every reason to believe that programs with well-developed inclusive philosophies and practices, integrated thoughtfully within general preschool activities, will yield more positive social integration outcomes. Yet, freeplay settings in which the nature of social exchanges and choice of play partner are not constrained by teachers' activities or limited through play structures, yield considerable social separation even in these quality programs. Why this might be the case and which approaches have the potential to reduce existing levels of social separation are discussed next.

\section{PROMOTING SOCIAL INTEGRATION}

Despite the fact that the psychological and related implications of social separation in inclusive settings are not fully understood, efforts to maximize social integration remain important for ideological and developmental reasons. From an ideological perspective, by encouraging the development of meaningful social relationships between children with and without disabilities during the early years, a foundation for constructing an inclusive community throughout the life span is established. Consistent with this expectation, research has indicated that parents perceive that inclusive early childhood settings do, in fact, promote acceptance of children with special needs, enhance sensitivity to individual differences, and encourage the development of peer relations and friendships among all children (Bailey \& Winton, 1987; Guralnick, 1994; Guralnick et al., 1995; Turnbull, Winton, Blacher, \& Salkind, 1982). From a developmental perspective, increased social integration implies increased positive social experiences with peers. Should this be realized, it is likely that children with developmental delays will reap numerous developmental benefits in relation to cognitive, communicative, and general prosocial skills as well as foster an emerging sense of self (Bates, 1975; Garvey, 1986; Har- tup, 1983; Howes, 1988; Rubin \& Lollis, 1988).

There also exists the possibility that increased social integration in classroom settings may have beneficial effects on social integration in community settings. There is certainly room for improvement as research has shown that the community-based peer social networks of young children with developmental delays are more limited than those of typically developing children (Byrne, Cunningham, \& Sloper, 1988; Guralnick, 1997a; Lewis, Feiring, \& Brooks-Gunn, 1987; Stoneman, Brody, Davis, \& Crapps, 1988). In addition, creating linkages between relationships formed with peers at preschool or daycare settings and those in their neighborhood are especially problematic for young children with developmental delays (Guralnick, 1997a). Similarly, even in inclusive settings, an all too common phenomenon is that social separation among parents tends to occur in accordance with the disability characteristics of their children (Bailey \& Winton, 1989; Stoneman, 1993).

\section{Ecological Approaches}

What factors contribute to the patterns of social integration that have been described? Classroom-based state-of-the-art inclusive practices can certainly play an important role. Quality programs, teachers well trained in inclusive practices, and innovative curricula can foster social integration (see Lamorey \& Bricker, 1993). Clearly, classroom environments, established by state-of-the-art practices, can remove barriers to full social integration and help set expectations about behavior and attitudes for all children. In turn, positive changes in relevant policy and corresponding administrative or organizational environments governing inclusive preschools can be beneficial (Peck, 1993), as these more distal ecological factors are among those that can potentially affect the quality of inclusive preschool practices. It remains to be seen, however, whether these approaches will be sufficient to dramatically alter the patterns of social separation described (see also File, 1994). 
It is perhaps the larger ecology of home, community, societal beliefs, attitudes, and actions toward individuals with disabilities that can exert a more substantial influence on children's social integration patterns (see Stoneman, 1993). Models analyzing how multiple ecological factors affect inclusive processes have been presented previously (Guralnick, 1982; Peck, 1993). For typically developing children in particular, the transmission of attitudes from children's families and communities with respect to an appreciation of diversity, for example, is a complex process. American society has made extraordinary advances in the past generation in fostering the inclusion of people with disabilities. However, inclusion for people with disabilities is certain to be affected by larger questions of how society is able to address the nature of diversity in general; an issue that remains contentious. The concern, of course, is that far too many typically developing children enter preschool settings with limited experiences with children with disabilities and a set of attitudes and expectations about children differing from themselves that are inconsistent with fostering social integration. The extent to which these initial expectations are altered by state-of-the-art inclusive practices and by contemporary experiences with children with disabilities in preschool settings and in the community to establish a new level of social integration remains a critical question for the future.

Despite the association likely to exist between these ecological factors and social integration outcomes, only limited experimentally-based information is available on this matter. Moreover, how these factors might affect the various dimensions of social integration identified in this paper has not been addressed. It is quite possible that instances of overt rejection and even certain aspects of exclusionary patterns directed toward children with developmental delays can be altered through changes in the larger ecology. Whether friendship patterns between children with and without delays can be altered by those same factors is clearly a far more difficult issue. Indeed, despite recognizing many potential advantages of inclusive settings, parents of children with disabilities continue to express concerns related to possible rejection of their child (Bailey \& Winton, 1987; Guralnick, 1994; Guralnick et al., 1995). Of particular concern is that their child's own behavior may contribute to this rejection in the preschool setting (Guralnick et al., 1995). In the following section, this and related issues are considered in the context of a more child-oriented focus to promote social integration.

\section{Child-Oriented Approaches}

A primary reason why altering friendship patterns or the extent to which diverse groups of children engage in more extended play episodes is likely to be most difficult is due to the fact that children's selection of play partners is generally based on common interests, abilities, experiences, and interaction styles (e.g., Rubin, Lynch, Coplan, Rose-Krasnor, \& Booth, 1994). Unfortunately, it has been well documented that even children with mild developmental delays manifest peer-related social interaction difficulties that extend beyond those expected on the basis of their developmental level (e.g., Guralnick \& Groom, 1987; Guralnick \& Weinhouse, 1984). These social competence problems are apparent even in inclusive settings. Accordingly, it is possible that these unusual peer interaction difficulties serve to limit the degree to which social integration occurs with typically developing chronological age mates.

The reasons for the peer-related social competence problems characteristic of children with mild developmental delays are not fully known. Their more limited social experiences with peers, especially the relative absence of more in-depth relationships with typically developing children in home and community settings both prior to and during the preschool years, may be partially responsible (Guralnick, 1997a; Stoneman, 1993). In addition, greater difficulties in regulating emotions during play with peers (Guralnick et al., 1998; Guralnick \& Paul-Brown, 1989), or with regard to specific social-cognitive processes (Guralnick, 1992) are possible explanations. Children with developmental delays struggle with the important social tasks of peer group 
entry, resolving conflicts, and maintaining play. More limited language abilities is another alternative (even when controlling for developmental level), although language level at this age within subgroups of mildly delayed children is not a strong correlate of peer-related social competence (e.g., Guralnick et al., 1996a).

Consequently, child-oriented intervention programs that can successfully foster the peerrelated social competence of children with mild developmental delays may serve to reduce the degree of social separation observed in inclusive settings. Unfortunately, it has been remarkably difficult to achieve sustained and generalizable changes in the peer-related social competence of children with disabilities (e.g., Odom, McConnell, \& McEvoy, 1992). It is likely that a comprehensive child-focused approach involving school, family, and community components will be needed to achieve meaningful outcomes (Guralnick \& Neville, 1997).

\section{A GENERAL MODEL OF INFLUENCES ON SOCIAL INTEGRATION}

All children bring to a social setting, such as an inclusive preschool, a set of social interaction skills, specific interests in certain social and nonsocial activities, expectations that others share their rule systems, a certain level to which they are willing to accept or overlook unexpected or even inappropriate behavior in their peers, and a respect for varying degrees of individual differences. In turn, these patterns reflect prior or ongoing experiences with peers and family members, especially parental beliefs, attitudes, and behaviors and, of course, their own unique social abilities. In inclusive preschool settings, from the perspective of typically developing children, the degree to which children with mild developmental delays (at any level of peer-related social competence) are socially integrated will depend upon these factors as well as specific experiences in the environment of the inclusive setting itself.

Figure 1 attempts to depict these complex interrelationships as they might influence the three social integration constructs identified in this paper as assessed in free-play situations. As illustrated in the model, the ultimate degree to which children with developmental delays, or perhaps children with disabilities in general, experience social integration in preschool settings is dependent upon four main factors. First are expectations with respect to establishing potential social relationships with children with disabilities by typically developing children that occur prior to participation in inclusive settings. These expectations are formed through yet little understood processes which transmit attitudes by parents and other family members toward people with disabilities, through a more general family atmosphere regarding acceptance and even celebration of diversity, and specific experiences with children (or people in general) with disabilities (see Prior Expectations in Figure 1). These specific experiences with individuals with disabilities are often arranged, or fail to be arranged as the case may be, by parents. As a consequence, there is likely to be a high correlation among the three components of "prior expectations." Not indicated in the model in Figure 1 are the overarching societal attitudes and beliefs and associated practices that can affect the three components of prior expectations. Clearly, as these larger ecological factors serve to encourage more positive attitudes and increase the likelihood of contact with children with disabilities, prior expectations will be influenced.

Second, these prior expectations are subject to modification through more contemporary experiences between children with and without disabilities in the home or community. Experiences occurring in the context of recreational, religious, or family organized social events that involve children with disabilities have the potential to modify these prior expectations. Most often, however, these prior expectations continue to exert their influence over time. They not only affect contemporary experiences in home and community, but may well affect whether parents select an inclusive preschool setting for their child in the first place. Similarly, these prior experiences of 


\section{Figure 1.}

A model depicting factors that influence social integration during free-play situations in inclusive preschool settings.

\section{Key Factors Influencing Social Integration}

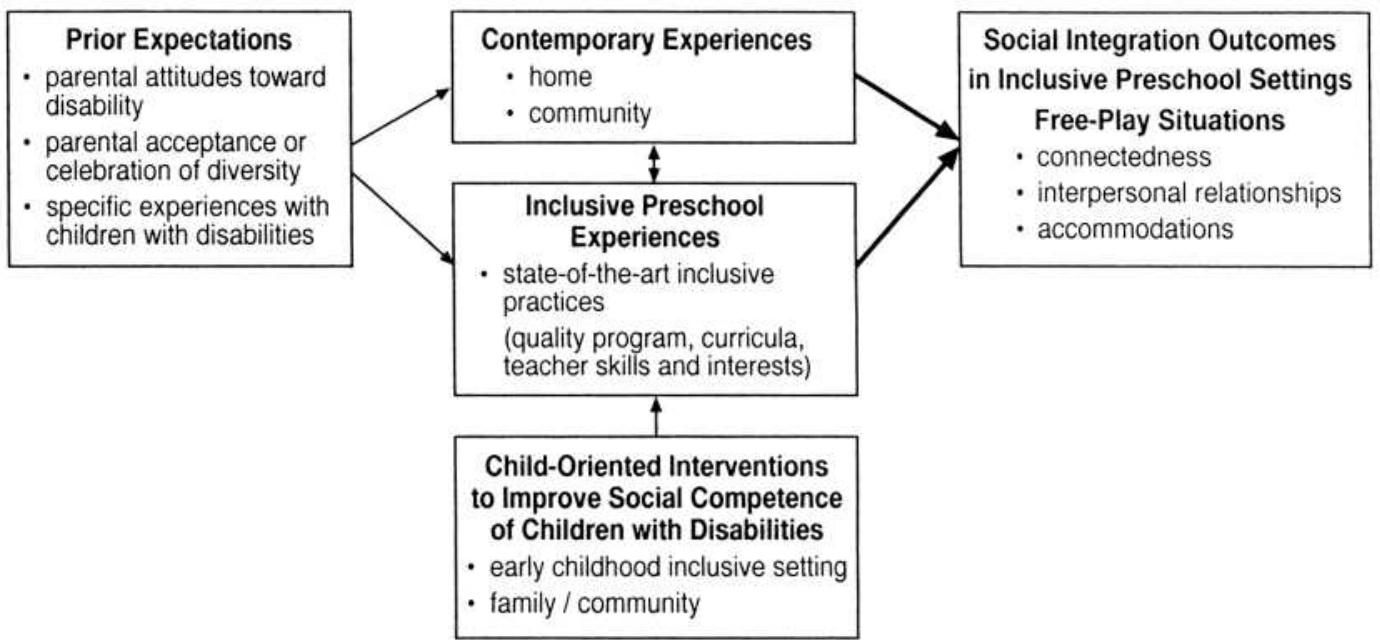

typically developing children may influence the actual social experiences that occur with children with disabilities in an inclusive preschool setting, including those that occur during free-play situations. These influences on typically developing children by prior expectations and by contemporary experiences are likely to be felt most strongly during the early phases of the inclusive preschool experience, but also may be subject to modification over time.

Accordingly, the third main factor influencing social integration consists of children's experiences in the inclusive preschool setting. The experiences of typically developing children in particular with children with disabilities may serve to modify negative prior expectations and will likely succeed in transforming children with more benign sets of expectations, but outcomes will depend on the quality of inclusive practices. Except for the most extreme prior expectations by typically developing children, it is here that teacher attitudes and behaviors, innovative curricula, and other practices can exert some degree of influence on social integration evaluated in the free-play setting. Important programmatic fac- tors that can alter social integration outcomes have been identified previously (Guralnick, 1981b), and can serve as a framework for evaluating social integration (Buysse \& Bailey, 1993).

The model further suggests (see doubleheaded arrow) the possibility of reciprocal influences between contemporary experiences in home and community settings and those occurring in the inclusive preschool setting. Friendships do indeed appear to be formed between children with disabilities and typically developing chronological-age mates in inclusive preschools which extend to the community (Guralnick et al., 1995). However, those linkages and perhaps the strength of the relationship as well are not as well developed for children with developmental delays (and likely children with other disabilities) in comparison to typically developing children (Guralnick, 1997a). Moreover, parents report that only a small percentage of their typically developing children have friends with a disability (Guralnick, 1997a). An interesting and potentially important path of influence, one not depicted in the model, is whether contemporary experiences in the inclusive preschool, 
home, and community alter parental attitudes toward diversity in general and to children with disabilities in particular.

The final factor that can influence social integration focuses exclusively on children with disabilities. As noted earlier, it has been difficult to develop successful intervention programs to enhance children's peer-related social competence, and insufficient resources are devoted to social development issues in preschool programs (Michnowicz, McConnell, Peterson, \& Odom, 1995). New approaches that consider the larger developmental-ecological contexts are emerging, however, and are attempting to address school, family, and community aspects of children's peer-related social development and social integration (Guralnick \& Neville, 1997). As reflected in the figure, these interventions may enhance the general social experiences and social competence of a child with a disability through highly specialized child-oriented programs designed for both the early childhood inclusive setting and the child's family and community. Should these interventions prove to be effective, there is every reason to expect to realize substantial improvements in social integration in preschool settings as evaluated in free-play situations.

Taken together, these four factors combine to influence the three constructs and related dimensions of social integration that have been described in this paper. As discussed, a coherent and robust body of evidence is available that adequately characterizes and provides a realistic portrayal of the social integration patterns of children with mild developmental delays with typically developing chronological age mates in inclusive settings. The extent to which these social integration patterns can be altered by any of the four factors in the model remains a vital question for the future. To be sure, there exist overarching ecological forces related to societal values, economic conditions, legal and legislative changes, or organizational issues that can affect each of these factors, particularly prior expectations. However, whatever the nature of these prevailing forces may be, social integration may benefit more from direct and con- centrated efforts on the three current factors related to home and community experiences with people with disabilities, the inclusive preschool setting, and interventions directed toward children with disabilities to improve their peer-related social competence. It is this activist agenda, carried out within a developmental ecological model and analyzed across the three social integration constructs identified in this paper that may provide a useful framework for future research on the nature and meaning of social integration for children with disabilities.

\section{REFERENCES}

Asher, S. R., Singleton, L. C., Tinsley, B. R., \& Hymel, S. (1979). A reliable sociometric measure for preschool children. Developmental Psychology, 15, 443-444.

Bailey, D. B., Jr., \& Winton, P. J. (1987). Stability and change in parents' expectations about mainstreaming. Topics in Early Childhood Special Education, 7, 73-88.

Bailey, D. B., Jr., \& Winton, P. J. (1989). Friendship and acquaintance among families in a mainstreamed day care center. Education and Training in Mental Retardation, 24, 107-113.

Bakeman, R., \& Brownlee, J. R. (1980). The strategic use of parallel play: A sequential analysis. Child Development, 51, 873-878.

Bates, E. (1975). Peer relations and the acquisition of language. In M. Lewis \& L. A. Rosenblum (Eds.), The origins of behavior: Vol. 4. Friendship and peer relations (pp. 259-292). New York: John Wiley \& Sons.

Blackmon, A. A., \& Dembo, M. H. (1984). Prosocial behaviors in a mainstreamed preschool. Child Study Journal, 14, 205-214.

Buysse, V., \& Bailey, D. B., Jr. (1993). Behavioral and developmental outcomes in young children with disabilities in integrated and segregated settings: A review of comparative studies. The Journal of Special Education, 26, 434-461.

Byrne, E. A., Cunningham, C. C., \& Sloper, P. (1988). Families and their children with Down's syndrome: One feature in common. London: Routledge.

Cavallaro, S. A., \& Porter, R. H. (1980). Peer preferences of at-risk and normally developing children in preschool mainstream classrooms. American Journal of Mental Deficiency, 84, 357-366.

Diamond, K., LeFurgy, W., \& Blass, S. (1993). Attitudes of preschool children toward their peers 
with disabilities: A year-long investigation in integrated classrooms. The Journal of Genetic Psychology, 154, 215-221.

Dunlop, K. H., Stoneman, Z., \& Cantrell, M. L. (1980). Social interaction of exceptional and other children in a mainstreamed preschool classroom. Exceptional Children, 47, 132-141.

File, N. (1994). Children's play, teacher-child interactions, and teacher beliefs in integrated early childhood programs. Early Childhood Research Quarterly, 9, 223-240.

Garvey, C. (1986). Peer relations and the growth of communication. In E. C. Mueller \& C. R. Cooper (Eds.), Process and outcome in peer relationships (pp. 329-345). Orlando, Florida: Academic Press.

Guralnick, M. J. (Ed.). (1978). Early intervention and the integration of handicapped and nonhandicapped children. Baltimore: University Park Press.

Guralnick, M. J. (1980). Social interactions among preschool children. Exceptional Children, 46, 248-253.

Guralnick, M. J. (1981a). The efficacy of integrating handicapped children in early education settings: Research implications. Topics in Early Childhood Special Education, 1(1), 57-71.

Guralnick, M. J. (1981b). Programmatic factors affecting child-child social interactions in mainstreamed preschool programs. Exceptional Education Quarterly, I(4), 71-91.

Guralnick, M. J. (1982). Mainstreaming young handicapped children: A public policy and ecological systems analysis. In B. Spodek (Ed.), Handbook of research on early childhood education (pp. 456-500). New York: The Free Press/MacMillan.

Guralnick, M. J. (1990). Major accomplishments and future directions in early childhood mainstreaming. Topics in Early Childhood Special Education, 10(2), 1-17.

Guralnick, M. J. (1992). A hierarchical model for understanding children's peer-related social competence. In S. L. Odom, S. R. McConnell, \& M. A. McEvoy (Eds.), Social competence of young children with disabilities: Issues and strategies for intervention (pp. 37-64). Baltimore: Brookes.

Guralnick, M. J. (1994). Mothers' perceptions of the benefits and drawbacks of early childhood mainstreaming. Journal of Early Intervention, $18,168-183$.

Guralnick, M. J. (1997a). The peer social networks of young boys with developmental delays. American Journal on Mental Retardation, 101, 595-612.
Guralnick, M. J. (1997b). Second generation research in the field of early intervention. In M. J. Guralnick (Ed.), The effectiveness of early intervention (pp. 3-22). Baltimore: Brookes.

Guralnick, M. J. (1998). The effectiveness of early intervention for vulnerable children: A developmental perspective. American Journal on Mental Retardation, 102, 319-345.

Guralnick, M. J., Connor, R., \& Hammond, M. (1995). Parent perspectives of peer relations and friendships in integrated and specialized programs. American Journal on Mental Retardation, 99, 457-476.

Guralnick, M. J., Connor, R., Hammond, M., Gottman, J. M., \& Kinnish, K. (1996a). Immediate effects of mainstreamed settings on the social interactions and social integration of preschool children. American Journal on Mental Retardation, 100, 359-377.

Guralnick, M. J., Connor, R., Hammond, M., Gottman, J. M., \& Kinnish, K. (1996b). The peer relations of preschool children with communication disorders. Child Development, 67, 471489.

Guralnick, M. J., Gottman, J. M., \& Hammond, M. A. (1996). Effects of social setting on the friendship formation of young children differing in developmental status. Journal of Applied Developmental Psychology, 17, 625-651.

Guralnick, M. J., \& Groom, J. M. (1985). Correlates of peer-related social competence of developmentally delayed preschool children. American Journal of Mental Deficiency, 90, 140-150.

Guralnick, M. J., \& Groom, J. M. (1987). The peer relations of mildly delayed and nonhandicapped preschool children in mainstreamed playgroups. Child Development, 58, 15561572.

Guralnick, M. J., \& Groom, J. M. (1988a). Friendships of preschool children in mainstreamed playgroups. Developmental Psychology, 24. 595-604.

Guralnick, M. J., \& Groom, J. M. (1988b). Peer interactions in mainstreamed and specialized classrooms: A comparative analysis. Exceptional Children, 54, 415-425.

Guralnick, M. J., \& Hammond, M. A. (in press). Sequential analysis of the social play of young children with mild developmental delays. Journal of Early Intervention.

Guralnick, M. J., \& Neville, B. (1997). Designing early intervention programs to promote children's social competence. In M. J. Guralnick (Ed.), The effectiveness of early intervention (pp. 579-610). Baltimore: Brookes. 
Guralnick, M. J., \& Paul-Brown, D. (1984). Communicative adjustments during behavior-request episodes among children at different developmental levels. Child Development, 55, 911-919.

Guralnick, M. J., \& Paul-Brown, D. (1986). Communicative interactions of mildly delayed and normally developing preschool children: Effects of listener's developmental level. Journal of Speech and Hearing Research, 29, 2-10.

Guralnick, M. J., \& Paul-Brown, D. (1989). Peerrelated communicative competence of preschool children: Developmental and adaptive characteristics. Journal of Speech and Hearing Research, 32, 930-943.

Guralnick, M. J., Paul-Brown, D., Groom, J. M., Booth, C. L., Hammond, M. A., Tupper, D. B., \& Gelenter, A. (1998). Conflict resolution patterns of preschool children with and without developmental delays in heterogeneous playgroups. Early Education and Development, 9, 49-77.

Hartup, W. W. (1983). Peer relations. In E. M. Hetherington (Ed.), P. H. Mussen (Series Ed.), Handbook of child psychology: Vol. 4. Socialization, personality, and social development (pp. 103-196). New York: Wiley.

Howes, C. (1988). Peer interaction of young children. Monographs of the Society for Research in Child Development, 53(1, Serial No. 217).

Ispa, J. (1981). Social interactions among teachers, handicapped children, and nonhandicapped children in a preschool. Journal of Applied Developmental Psychology, 1, 231-250.

Ispa, J., \& Matz, R. D. (1978). Integrating handicapped preschool children within a cognitively oriented program. In M. J. Guralnick (Ed.), Early intervention and the integration of handicapped and nonhandicapped children (pp. 167-190). Baltimore: University Park Press.

Jenkins, J. R., Odom, S. L., \& Speltz, M. L. (1989). Effects of social integration on preschool children with handicaps. Exceptional Children, 55, 420-428.

Lamorey, S., \& Bricker, D. D. (1993). Integrated programs: Effects on young children and their parents. In C. A. Peck, S. L. Odom, \& D. D. Bricker (Eds.), Integrating young children with disabilities into community programs (pp. 249270). Baltimore: Brookes.

Lewis, M., Feiring, C., \& Brooks-Gunn, J. (1987). The social networks of children with and without handicaps: A developmental perspective. In S. Landesman \& P. Vietze (Eds.), Living environments and mental retardation (pp. 377400). Washington, DC: American Association on Mental Retardation.
Michnowicz, L. L., McConnell, S. R., Peterson, C. A., \& Odom, S. L. (1995). Social goals and objectives of preschool IEPs: A content analysis. Journal of Early Intervention, 19, 273282.

Nabors, L. (1997). Playmate preferences of children who are typically developing for their classmates with special needs. Mental Retardation, $35,107-113$.

Newcomb, A. F., \& Bagwell, C. L. (1995). Children's friendship relations: A meta-analytic review. Psychological Bulletin, 117, 306-347.

Odom, S. L., McConnell, S. R., \& McEvoy. (Eds.). (1992). Social competence of young children with disabilities: Issues and strategies for intervention. Baltimore: Brookes.

Peck, C. A. (1993). Ecological perspectives on the implementation of integrated early childhood programs. In C. A. Peck, S. L. Odom, \& D. D. Bricker (Eds.), Integrating young children with disabilities into community programs (pp. 315). Baltimore: Brookes.

Peterson, N. L., \& Haralick, J. G. (1977). Integration of handicapped and nonhandicapped preschoolers: An analysis of play behavior and social interaction. Education and Training of the Mentally Retarded, 12, 235-245.

Porter, R. H., Ramsey, B., Tremblay, A., Iaccobo, M., \& Crawley, S. (1978). Social interactions in heterogeneous groups of retarded and normally developing children: An observational study. In G. P. Sackett (Ed.), Observing behavior: Vol. 1. Theory and applications in mental retardation (pp. 311-328). Baltimore: University Park Press.

Ramsey, P. G. (1995). Changing social dynamics in early childhood classrooms. Child Development, 66, 764-773.

Rubin, K. H., \& Lollis, S. P. (1988). Origins and consequences of social withdrawal. In J. Belsky \& T. Nezworski (Eds.), Clinical implications of attachment (pp. 219-252). Hillsdale, N.J.: Lawrence Erlbaum.

Rubin, K. H., Lynch, D., Coplan, R., Rose-Krasnor, L., \& Booth C. L. (1994). "Birds of a feather. .": Behavioral concordances and preferential personal attractions in children. Child Development, $65,1778-1785$.

Shatz, M., \& Gelman, R. (1973). The development of communication skills: Modifications in the speech of young children as a function of listener. Monographs of the Society for Research in Child Development, 38(5, Serial No. 152).

Stoneman, Z. (1993). The effects of attitude on preschool integration. In C. A. Peck, S. L. Odom, \& D. D. Bricker (Eds.), Integrating young chil- 
dren with disabilities into community programs (pp. 223-248). Baltimore: Brookes.

Stoneman, Z., Brody, G. H., Davis, C. H., \& Crapps, J. M. (1988). Childcare responsibilities, peer relations, and sibling conflict: Older siblings of mentally retarded children. American Journal on Mental Retardation, 93, 174183.

Strain, P. S. (1984). Social behavior patterns of nonhandicapped and nonhandicapped-developmentally disabled friend pairs in mainstream preschools. Analysis and Intervention in Developmental Disabilities, 4, 15-28.

Strayer, F. F. (1980). Social ecology of the preschool peer group. In W. A. Collins (Ed.), The Minnesota symposia on child psychology: Vol. 13. Development of cognition, affect, and social relations (pp. 165-196). Hillsdale, NJ: Lawrence Erlbaum.
Turnbull, A. P., Winton, P. J., Blacher, J., \& Salkind, N. (1982). Mainstreaming in the kindergarten classroom: Perspectives of parents of handicapped and nonhandicapped children. Journal of the Division of Early Childhood, 6, 14-20.

White, B. N. (1980). Mainstreaming in grade school and preschool: How the child with special needs interacts with peers. In T. M. Field, S. Goldberg, D. Stern, \& A. M. Sostek (Eds.), High-risk infants and children: Adult and peer interactions (pp. 347-371). New York: Academic Press.

Address correspondence to Michael J. Guralnick, Ph.D., Center on Human Development and Disability, Box 357920, University of Washington, Seattle, WA 98195-7920,

Email: mjgural@u.washington.edu. 